\title{
Essential reading from the editor's desk
}

\author{
T. Vanuytsel ${ }^{1-2}$, C. Reenaers ${ }^{3}$ \\ (1) Gastroenterology and Hepatology, University Hospitals Leuven, KU Leuven, Leuven, Belgium; (2) Translational Research in Gastrointestinal Diseases (TARGID), \\ KU Leuven, Leuven, Belgium; (3) Gastroenterology, University Hospital Liège, Liège, Belgium.
}

Keywords: Disorders of Gut-Brain Interaction, Low FODMAP diet, Probiotics, papillotomy, COVID-19,

Functional gastrointestinal disorders like irritable bowel syndrome (IBS) and functional dyspepsia (FD) are highly prevalent with a significant impact on the quality of life (1). Unfortunately, the pathophysiology remains poorly understood even if it is clear that a disturbed bidirectional communication between the brain and the gut, i.e. the brain-gut axis, is involved (2). These insights led to the renaming from functional gastrointestinal disorders to 'disorders of gut-brain interaction' (DGBI) since the last iteration of the Rome criteria (3). In the current issue of the Acta Gastro-enterologica Belgica, Van Nieuwenhove and colleagues report an increased prevalence of IBS and a similar tendency for FD in 44 patients with liver steatosis vs. a control group of 33 patients with a normal liver on ultrasound (4). Their findings could not be explained by confounders such as diabetes mellitus, BMI or concomitant medication. The pathophysiology of these findings is unclear, but the authors hypothesize that dysbiosis of the microbiome may be a common denominator in both conditions, explaining the enriched prevalence of DGBI in steatosis. Even if replication in a larger cohort and further mechanistic studies are needed, this study provides further insight in the complex epidemiology and pathophysiology of DGBI and also stimulates clinicians to pay attention to bowel symptoms in steatosis patients. One of the most effective treatments for IBS is the low FODMAP diet, in which fermentable oligo-, di- and monosaccharides and polyols are avoided. Even if it is advised to involve an experienced dietitian to guide this complex diet, many physicians are tempted to explain the principles of the diet themselves, often supplemented with an information folder. Van Ouytsel and colleagues tested whether this approach was effective (5). The large majority of the 35 included patients understood the instructions, but only half of them followed the diet regularly and $69 \%$ wanted follow-up by a dietitian. These data confirm earlier reports that dietitians are indispensable for guiding the reintroduction and long-term phase after the initial elimination phase of the low FODMAP diet (6), but also clearly show that patients themselves are willing to be guided by a dietitian. Probiotics are another popular therapeutic strategy for IBS patients. In an open label study in 77 IBS patients, Mokthar et al. report improved symptoms in virtually all patients, which was accompanied by a reduction in intestinal transit time and a drop in plasma cytokine levels after one month treatment with a milk drink containing two probiotic Lactobacillus strains (7). It is evident that these data need to be confirmed in a randomized controlled trial, but the study provides additional support and mechanistic insight to the use of probiotics in DGBI. Switching gears pelvic floor dysfunction, another DGBI, Özin and colleagues investigated predictive factors for success after biofeedback therapy (8). Patients with increased voluntary squeeze pressures during anorectal manometry and those with increased squeeze pressures after biofeedback had higher likelihood of symptom improvement, suggesting that pelvic floor musculature training should be an integral part of biofeedback therapy.

Difficult biliary cannulation during ERCP has been defined by the European Society of Gastrointestinal Endoscopy (ESGE) as the presence of one or more of the following criteria: more than 5 contacts with he papilla during the cannulation attempts; more than 5 minutes of attempting to cannulate the papilla after visualization and more than one unintended cannulation of the pancreatic duct (9). Common causes for difficult cannulation include insufficient experience of the endoscopist, abnormal anatomy or malignant infiltration. In the current issue of our journal, Cankurtaran and colleagues have investigated the impact of a previous cholecystectomy on the cannulation process, based on their clinical experience that cannulation is indeed more difficult in these patients (10). They encountered a difficult cannulation in one third of patients after cholecystectomy compared to $19 \%$ in patients without cholecystectomy. Mandavdhare et al. investigated an early pre-cut papillotomy after 5 minutes to a delayed pre-cut papillotomy after 15 minutes in a randomized controlled trial (11). They found a similar success and adverse events rate but a lower radiation exposure in the early papillotomy group. However, pre-cut papillotomy should only be performed by endoscopists who achieve successful cannulation in more than $80 \%$ of patients with standard techniques, as advised by the ESGE (9).

Correspondence to : Tim Vanuytsel, MD, PhD, Herestraat 49, box 701, 3000
Leuven, Belgium. Phone: +32 16 341973 , Fax: +32 16344419 . Email: tim.vanuytsel@uzleuven.be 
We would like to draw your attention to an extensive review article on global differences in hepatitis $\mathrm{C}$ by Guntipalli and colleagues in which prevalence, genotypes and management strategies are discussed in Western countries, but also in developing economies (12). Finally, we highly recommend a review article on the impact of COVID-19 on the training of gastroenterology fellows, a topic which is important for all of us in these challenging times (13).

The entire editorial board wishes you a pleasant reading with these highlighted and many other interesting and thought-provoking articles and we look forward to meeting all of you at the next Belgian Week of Gastroenterology in February 2022.

\section{References}

1. SPERBER A. D., BANGDIWALA S. I., DROSSMAN D. A., GHOSHAL U. C., SIMREN M., TACK J., et al. Worldwide Prevalence and Burden of Functional Gastrointestinal Disorders, Results of Rome Foundation Global Study. Gastroenterology, 2021, 160(1): 99-114 e3.

2. BLACK C. J., DROSSMAN D. A., TALLEY N. J., RUDDY J.,FORD A. C. Functional gastrointestinal disorders: advances in understanding and management. Lancet, 2020, 396(10263): 1664-1674.

3. DROSSMAN D. A.,HASLER W. L. Rome IV-Functional GI Disorders: Disorders of Gut-Brain Interaction. Gastroenterology, 2016, 150(6): 1257-61.

4. VAN NIEUWENHOVE T., RASSCHAERT G., KHARAGJITSINGH A., KEYMEULEN B., REYNAERT H.,KINDT S. The prevalence of disorders of the gut-brain axis in type 2 diabetes mellitus patients with metabolic dysfunction-associated fatty liver disease: an observational study. Acta Gastroenterol Belg, 2021, 84(4): 541+547.
5. VAN OUYTSEL P., SZALAI A., VAN GOSSUM A., ARVANITAKIS M.,LOUIS H. Feasibility of a low FODMAPs diet without initial dietician intervention in the management of patients with irritable bowel syndrome: a prospective study. Acta Gastroenterol Belg, 2021,8 4(4): 593-600.

6. TUCK C. J., REED D. E., MUIR J. G.,VANNER S. J. Implementation of the low FODMAP diet in functional gastrointestinal symptoms: A real-world experience. Neurogastroenterol Motil, 2020,32(1):e13730.

7. MOKTHAR N., JAAFAR N., ALFIAN E., MOHD RATHI N., ABDUL RANI R.,RAJA ALI R. Clinical assessment and cytokines level in constipation-predominant irritable bowel syndrome participants treated with Lactobacillus-containing cultured milk drink. Acta Gastroenterol Belg, 2021, 84(4): 585-591.

8. ÖZIN Y., ÖZTÜRK Ö., TENLIK I., YÜKSEL S., BACAKSIZ F., ARI D., et $a l$. Efficacy of combination of biofeedback therapy and pelvic floor muscle training in dyssynergic defecation. Acta Gastroenterol Belg, 2021, 84(4): 577-583.

9. TESTONI P. A., MARIANI A., AABAKKEN L., ARVANITAKIS M., BORIES E., COSTAMAGNA G., et al. Papillary cannulation and sphincterotomy techniques at ERCP: European Society of Gastrointestinal Endoscopy (ESGE) Clinical Guideline. Endoscopy, 2016, 48(7): 657-83.

10. CANKURTARAN R., ATALAY R., POLAT Y., KIVRAKOGLU F., TAHTACI M.,ERSOY O. Is Cholecystectomy a cause of difficult biliary cannulation in endoscopic retrograde cholangiopancreatography? Acta Gastroenterol Belg, 2021, 84(4): 563-569.

11. MANDAVDHARE H., SHAH J., KAKADIYA R., KUMAR P., GUPTA P., SINGH H., et al. A pilot randomized trial to study the success rate of early precut fistulotomy and its effect on radiation dose in patients with difficult biliary cannulation. Acta Gastroenterol Belg, 2021, 84(4): 557-561.

12. GUNTIPALLI P., PAKALA R., KUMARI GARA S., AHMED F., BHATNAGAR A., ENDAYA CORONEL M., et al. Worldwide prevalence, genotype distribution and management of hepatitis C. Acta Gastroenterol Belg, 2021, 84(4): 637-656.

13. EKMEKTZOGLOU K., TZIATZIOS G., SIAU K., PAWLAK K., ROKKAS T., TRIANTAFYLLOU K., et al. Covid-19: exploring the "new normal" in gastroenterology training. Acta Gastroenterol Belg, 2021, 84(4): 627-635. 